\title{
Recruitment of Early Postnatal Parvalbumin-Positive Hippocampal Interneurons by GABAergic Excitation
}

\author{
Jonas-Frederic Sauer and Marlene Bartos \\ Institute of Medical Sciences, University of Aberdeen, Aberdeen AB25 2ZD, United Kingdom
}

GABAergic synaptic inputs targeting cortical principal cells undergo marked changes in their functional properties from depolarizing at early postnatal life to hyperpolarizing at mature stages. In contrast, the nature of $\mathrm{GABA}_{\mathrm{A}}$ receptor-mediated signaling in interneurons during maturation of neuronal networks is controversial. By using gramicidin perforated-patch and whole-cell recordings from LIM homeobox 6 (Lhx6)-positive dentate gyrus perisomatic-targeting parvalbumin-expressing interneurons (PV-INs), we show that signaling at first formed GABAergic synapses at postnatal day 3 (P3) is excitatory and switches to shunting during the course of the first to second postnatal week. GABAergic synaptic inputs at P3-P6 reliably evoke action potentials in 65\% of Lhx6-EGFP-expressing perisomatic-targeting cells and boost spike induction upon conjoint activation of glutamatergic fibers. Thus, GABAergic inputs change their functional role during maturation. They facilitate the recruitment of perisomatic-targeting INs in early postnatal circuits when network connectivity and synaptic glutamate receptor-mediated excitation are low and control spike timing at later stages when connectivity and glutamate-mediated drive are high.

\section{Introduction}

Mature hippocampal networks fulfill the sophisticated task of encoding spatial and episodic information. GABAergic inhibitory interneurons (INs), specifically fast-spiking perisomatictargeting parvalbumin-expressing interneurons (PV-INs), seem to play a crucial role in this computation (Bartos et al., 2007). They are recruited by converging excitatory glutamatergic inputs (Geiger et al., 1997; Fuchs et al., 2007) and are highly interconnected (Freund and Buzsáki, 1996; Bartos et al., 2002), a synaptic arrangement that allows perisomatic-targeting INs to provide feedforward and feedback inhibition in the neuronal circuit. By means of their fast and strong inhibitory output synapses (Bartos et al., 2002, 2007) and in particular by the shunting nature of the postsynaptic conductance (Kraushaar and Jonas, 2000; Vida et al., 2006), perisomatic-targeting INs control the precise timing and frequency of action potentials generated in their target cells (Vida et al., 2006; Mann and Paulsen, 2007), an important requirement for the emergence of rhythmic activity patterns and information processing in hippocampal networks (Bartos et al., 2007; Mann and Paulsen, 2007).

During early postnatal development, however, perisomatictargeting INs seem to contribute differently to network activity. Their synaptic output is slow and weak, connectivity among perisomatic-targeting INs is low and glutamatergic excitation by

Received Aug. 21, 2009; revised 0ct. 27, 2009; accepted Nov. 9, 2009.

This work was supported by grants to M.B. from the Royal Society, the University of Aberdeen, and the Volkswagenstiftung (I/78563-564) and by the Northern Research Partnership (J.S.). We thank M. Frotscher, M. Strüber, and I. Vida for critical comments on earlier versions of the manuscript. S. Sambandan participated in the initial recordings of Lhx6-EGFP cells. We are also grateful to V. Pachnis for kindly providing the Lhx6 antibody, to A. Kulik for performing perfusions, and to $S$. Becherer for technical assistance.

Correspondence should be addressed to Dr. Marlene Bartos at the above address. E-mail: m.bartos@abdn.ac.uk. D0I:10.1523/JNEUROSCI.4125-09.2010

Copyright $\odot 2010$ the authors $\quad 0270-6474 / 10 / 300110-06 \$ 15.00 / 0$ local principal cells (PCs) is infirmly established (Doischer et al., 2008). One possibility how perisomatic-targeting INs could be recruited and impact on network function at early development is that the nature of GABAergic inputs is depolarizing. Indeed, early postnatal $\mathrm{GABA}_{\mathrm{A}}$-mediated signals depolarize PCs (Leinekugel et al., 1995; Hollrigel et al., 1998; Ben-Ari, 2002) and support intracellular $\mathrm{Ca}^{2+}$ rise via NMDA receptors and voltage-dependent $\mathrm{Ca}^{2+}$ channels (Owens et al., 1996; Garaschuk et al., 1998), a major premise for the maturation of early postnatal cortical networks (Ben-Ari, 2002; Sipilä et al., 2009).

Despite the well established shift of GABAergic signaling in PCs from depolarization to hyperpolarization during development (Leinekugel et al., 1995; Hollrigel et al., 1998; Rivera et al., 1999; Ben-Ari, 2002), the situation in cortical INs is highly controversial (Leinekugel et al., 1995; Banke and McBain, 2006; Rheims et al., 2008; Tyzio et al., 2008). We therefore addressed this open question in the dentate gyrus (DG) of transgenic mice in which the enhanced green fluorescent protein (EGFP) is selectively expressed under the control of the LIM homeobox 6 (Lhx6) promoter thereby predominantly labeling $\mathrm{PV}^{+}$cells (Cobos et al., 2005). We chose the DG because it matures later than other cortical areas (Altman and Das, 1965) and thus allows the investigation of early changes in GABAergic signaling in acute brain slices at postnatal stages. We show that $\mathrm{GABA}_{\mathrm{A}}$ receptor-mediated signaling in Lhx6-EGFP-containing perisomatic-targeting cells is excitatory in the early postnatal [postnatal day 3 (P3)-P6] DG and switches to shunting during the course of further maturation, contrasting recent investigations in unidentified INs in the CA3 area, where inhibition remains shunting throughout postnatal development (Banke and McBain, 2006; Tyzio et al., 2008). Furthermore, we provide evidence that excitatory GABAergic transmission is an efficient mechanism for the recruitment of perisomatic-targeting cells at early postnatal stages when gluta- 
matergic excitatory drive and network connectivity are low (Doischer et al., 2008).

\section{Materials and Methods}

Electrophysiology. Hemizygous Lhx6-EGFP transgenic 0- to 21-d-old mice (www.gensat.org) were killed by decapitation without anesthesia in accordance with national legislation. Brains were transferred to ice-cold slicing solution containing (in $\mathrm{mm}$ ) $\mathrm{NaCl} 87, \mathrm{NaHCO}_{3} 25, \mathrm{KCl} 2.5$, $\mathrm{NaH}_{2} \mathrm{PO}_{4} 1.25$, glucose 10 , sucrose $75, \mathrm{CaCl}_{2} 0.5$, and $\mathrm{MgCl}_{2} 7$ (aerated with $\left.95 \% \mathrm{O}_{2} / 5 \% \mathrm{CO}_{2}\right)$. Transverse hippocampal slices $(300 \mu \mathrm{m})$ were cut with a vibratome (DTK-1000, Dosaka; VT-1200, Leica), recovered (30 $\mathrm{min}, 34^{\circ} \mathrm{C}$ ) in artificial CSF (ACSF) consisting of (in $\mathrm{mm}$ ) $\mathrm{NaCl} 125$, $\mathrm{NaHCO}_{3} 25, \mathrm{KCl} 2.5, \mathrm{NaH}_{2} \mathrm{PO}_{4} 1.25$, glucose 25, $\mathrm{CaCl}_{2}$ 2, and $\mathrm{MgCl}_{2} 1$ (equilibrated with $95 \% \mathrm{O}_{2} / 5 \% \mathrm{CO}_{2}$ ), then stored at room temperature. Patch pipettes (wall thickness: $0.5-0.7 \mathrm{~mm}$ ) were pulled from borosilicate glass tubing (Hilgenberg; Flaming-Brown P-97 puller, Sutter Instruments). Pipettes for whole-cell recordings were filled with internal solution composed of (in mM) HEPES $10, \mathrm{MgCl}_{2} 2, \mathrm{Na}_{2} \mathrm{ATP}$ 2, EGTA 0.1, and either $\mathrm{KCl} 40$, K-gluconate 110 or $\mathrm{KCl} 20$, K-gluconate 120 (resistance: 2-13 M $\Omega$ ). To set the reversal potential of IPSPs to a value measured at P3-P6 and P18-P21, respectively, pipette solutions containing either (in mM) HEPES 10, $\mathrm{KCl} 42$, K-gluconate 108, $\mathrm{MgCl}_{2}$ 2, $\mathrm{Na}_{2} \mathrm{ATP} 2$, EGTA 0.1 ("early postnatal" solution) or HEPES 10, KCl 11.2, K-gluconate $128.8, \mathrm{MgCl}_{2} 2, \mathrm{Na}_{2} \mathrm{ATP} 4, \mathrm{Na}_{2}$-phosphocreatine 7 , and EGTA 0.1 ("juvenile" solution) were used. The resulting reversal potentials were $-31 \pm 1 \mathrm{mV}$ ("early postnatal," 3 cells) and $-56 \pm 2 \mathrm{mV}$ ("juvenile," 2 cells) (data not shown). The $\mathrm{pH}$ of internal solutions was adjusted to $7.2(\mathrm{KOH})$. Biocytin $(1-4 \mathrm{mg} / \mathrm{ml})$ was added for morphological recovery. Lhx6-EGFP-expressing neurons were identified by epifluorescence and recorded at $30-34^{\circ} \mathrm{C}$ under visual control (infrared differential interference contrast videomicroscopy) using Axopatch 200B or MultiClamp 700B amplifiers (Molecular Devices). In action potential initiation experiments neurons were held at their resting membrane potential ( $V_{\text {rest }} ;$ measured in $I=0$ mode after break through), in all other experiments at $-70 \mathrm{mV}$. Only neurons with a seal resistance/input resistance $\left(R_{\mathrm{i}}\right)>3$ were considered for $V_{\text {rest }}$ measurement. Extracellular stimulation $(0.2 \mathrm{~ms} ; 1-74 \mathrm{~V})$ was performed with pipettes containing the following (in mM): $\mathrm{HEPES} 5, \mathrm{NaCl} 135, \mathrm{KCl} 5.4, \mathrm{CaCl}_{2} 1.8$, and $\mathrm{MgCl}_{2} 1$. Extracellular stimulation intensity in Figure 3, $A$ and $B$, was stepwise increased to examine whether synaptic inputs can evoke action potentials. In Figure 3, $C$ and $D$, intensity was set to a value resulting in $~ 50 \%$ action potential induction probability. Glutamatergic transmission was blocked by bath-applied 6-cyano-7-nitroquinoxaline-2,3-dione (CNQX, 10-20 $\mu \mathrm{M}$ ) or kynurenic acid $(2-4 \mathrm{~mm})$. GABA $\mathrm{A}_{\mathrm{A}}$ receptors were blocked with SR95531 $(2-5 \mu \mathrm{M})$ or bicuculline methiodide $(10 \mu \mathrm{M})$. Signals were filtered at $5-10 \mathrm{kHz}$ and digitized at $20-40 \mathrm{kHz}$ with a Power1401 laboratory interface (Cambridge Electronic Design). Series resistance $(6-43 \mathrm{M} \Omega)$ was compensated in current-clamp $(100 \%, 1 \mu \mathrm{s}$ time lag). For perforated-patch recordings pipettes were tip-filled with a solution containing (in $\mathrm{mM}$ ) HEPES $10, \mathrm{KCl} 100, \mathrm{MgCl}_{2} 5$, and glucose 5 and back-filled with the same solution further comprising Alexa Fluor $488(50-200 \mu \mathrm{M})$ and gramicidin D (Sigma, $15-45 \mu \mathrm{g} / \mathrm{ml}$ ) or A (Merck, $50 \mu \mathrm{g} / \mathrm{ml})$. Recordings were obtained after series resistance had stabilized between 80 and $100 \mathrm{M} \Omega$. Evoked $\mathrm{GABA}_{\mathrm{A}}$ receptor-mediated IPSPs were recorded at varying holding potentials $\left(V_{\text {hold }}\right)$ and the peak amplitude of average IPSPs (2-14 traces) was plotted as a function of $V_{\text {hold }}$. Reversal potential of synaptically evoked IPSPs $\left(E_{\text {syn }}\right)$ was determined from the crossing of a second order polynomial function fitted to the data with the $0 \mathrm{mV}$ line. Action potential firing patterns were recorded during current injections of increasing amplitude lasting $1 \mathrm{~s}$ (50 pA increments). Action potential threshold $\left(V_{\mathrm{thr}}\right)$ was defined as the potential where the voltage slope exceeded $20 \mathrm{~V} \cdot \mathrm{s}^{-1}$ (Doischer et al., 2008). $R_{\mathrm{i}}$ was derived from the average current in response to $500 \mathrm{~ms}$ depolarizing $10 \mathrm{mV}$ test pulses. To assess the membrane time constant $\left(\tau_{\mathrm{m}}\right)$, voltage trajectories (127-300 traces) resulting from $400 \mathrm{~ms}$ depolarizing pulses were averaged, the 100 to $5 \%$ epoch of the peak voltage change was logarithmically transformed, and the final $10 \mathrm{~ms}$ were fitted with a linear function. Data were acquired and analyzed with custom made programs (data acquisition: F-pulse, running under Igor Pro 5, U. Fröbe, University of Freiburg, Freiburg,
Germany; data analysis: Stimfit32, C. Schmidt-Hieber, University College London, London, UK, and P. Jonas, University of Freiburg). Statistical significance was assessed with a two-tailed Student's $t$ test, a nonparametric two-tailed Mann-Whitney test or a one-way ANOVA analysis computed in SigmaPlot 11 (Systat Software). Values are given as mean \pm SEM.

Immunohistochemistry. Staining of biocytin-filled neurons with streptavidin (Alexa Fluor 568 or Alexa Fluor 647 conjugate, Invitrogen, 1:500) or 3,3-diaminobenzidine tetrahydrochloride (DAB) as chromogen was performed as described previously (Bartos et al., 2002). PVlabeling was done with a polyclonal rabbit-anti-PV primary (Swant, $1: 1000$ ) and goat-anti-rabbit Cy3 secondary antibody (Jackson ImmunoResearch, 1:1000). Slices were fixed after recording in 4\% paraformaldehyde (PFA) overnight. After washing in phosphate buffer and PBS, slices were blocked in PBS $+10 \%$ normal goat serum (NGS, $60 \mathrm{~min}$ ). Primary antibody was applied in PBS $+0.3 \%$ Triton X-100 + 5\% NGS for $24 \mathrm{~h}$ at room temperature, and secondary antibody was incubated together with streptavidin conjugate in PBS $+0.3 \%$ Triton X-100 + 3\% NGS for $24 \mathrm{~h}$ at $4^{\circ} \mathrm{C}$. Perfusion of mice was performed as described by Doischer et al. (2008). For Lhx6 immunostainings, brains of perfused mice were postfixed overnight in $4 \%$ PFA and embedded in $4 \%$ agar. Transverse hippocampal slices $(50 \mu \mathrm{m})$ were cut with a vibratome (VT1000S, Leica). Slices were permeabilized with $0.4 \%$ Triton X-100 in PBS for 30 min and blocked with $0.2 \%$ Triton X-100 and 4\% NGS for 60 min. Primary antibody incubation (rabbit-anti-Lhx6, V. Pachnis, National Institute for Medical Research, London, UK; 1:500) was done overnight at $4^{\circ} \mathrm{C}$, secondary antibody was incubated for $2-3 \mathrm{~h}$ at room temperature. Slices were mounted in Mowiol. Colocalization of Lhx6 and EGFP was analyzed with LSM image browser (Zeiss).

\section{Results}

\section{Lhx6-EGFP is predominantly expressed in fast-spiking perisomatic-targeting $\mathrm{PV}^{+}$cells}

The identification of hippocampal perisomatic-targeting cells during the first postnatal week is challenging because anatomical hallmarks such as the dense axonal arbor confined to the principal cell layer are poorly developed before $\sim$ P6 (Doischer et al., 2008), and PV is not expressed before $\sim$ P10 (Du et al., 1996). Thus, to obtain recordings from perisomatic-targeting cells in acute hippocampal slices from the day of birth (P0) onwards, we used the Lhx6-EGFP mouse line. Previous studies have indicated that Lhx6-EGFP is expressed in a subset of GABAergic cells before birth that differentiate postnatally into $\mathrm{PV}^{+}$cortical neurons (Cobos et al., 2005). We first confirmed that Lhx6-positive cells are EGFP labeled in the DG (Fig. 1). In slices of juvenile mice, EGFP-expressing neurons were mainly located in or close to the granule cell layer (gcl) (Fig. 1A). Antibody-labeling revealed that $98.5 \pm 0.8 \%$ of EGFP-positive cells colocalize Lhx6 and $53.1 \pm$ 2.0\% of Lhx6-expressing neurons are positive for EGFP (Fig. $1 \mathrm{~A}$ ) (266 EGFP cells, 487 Lhx6 cells; 11 slices, 2 P19 animals). Thus, EGFP is a reliable marker for approximately half of the Lhx6expressing cell population.

Next we examined whether Lhx6-EGFP-containing neurons comprise perisomatic-targeting cells by combining whole-cell recordings in acute hippocampal slices of P17-P21 mice with intracellular labeling and subsequent histological processing. Morphological analysis demonstrated that $80 \%$ of the recorded neurons were perisomatic-targeting cells with axon collaterals largely confined to the gcl (57 of 71 cells) (Fig. $1 B$; supplemental Fig. $1 \mathrm{~A}$, available at www.jneurosci.org as supplemental material). The remaining $20 \%$ comprised dendrite-inhibiting INs with axons in the molecular layer (supplemental Fig. $1 B$, available at www.jneurosci.org as supplemental material) (Freund and Buzsáki, 1996). Triple labeling revealed that identified Lhx6EGFP-containing perisomatic-targeting INs colocalize PV (10 of 

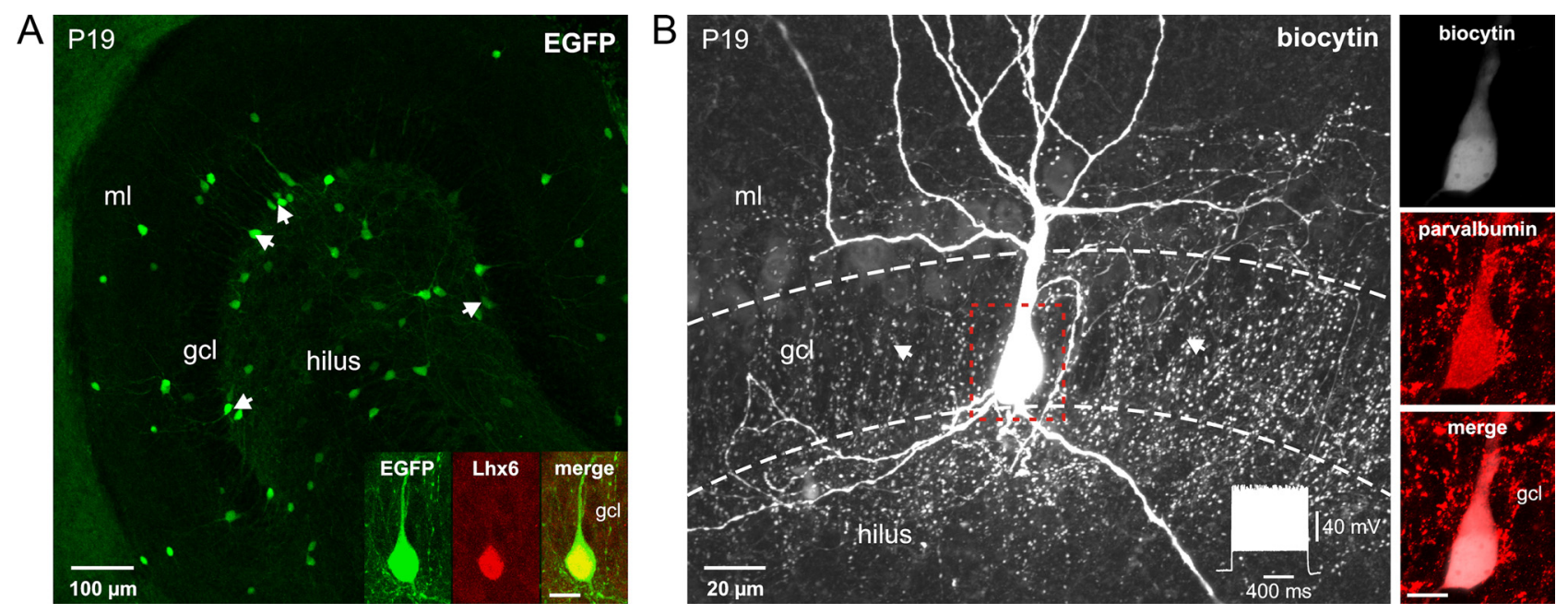

Figure 1. Lhx6-EGFP is reliably expressed in fast-spiking perisomatic-targeting PV ${ }^{+}$cells. A, Confocal image stack from a horizontal section ( $\left.50 \mu \mathrm{m}\right)$ through the DG of a juvenile Lhx6-EGFP mouse. Note the high density of Lhx6-EGFP-positive somata at the gcl-hilus border (arrows). Inset, Confocal image demonstrating colocalization of EGFP and Lhx6 detected with a primary antibody and visualized using a secondary antibody conjugated to Cy3. Scale bar, $20 \mu \mathrm{m}$. B, Left, A single Lhx6-EGFP-positive neuron was filled with biocytin during whole-cell recording and visualized subsequently. The dense axonal arborizations in the gcl (arrows) identify this neuron as a perisomatic-targeting cell. The selected somatic area (red box) is shown on the right at higher magnification. Inset, Perisomatic-targeting cells had a typical fast-spiking non-adapting discharge pattern $\left(600 \mathrm{pA}, 1 \mathrm{~s} ; V_{\text {hold }}-70 \mathrm{mV}\right)$. Right, Confocal image stack of the same cell stained against parvalbumin, a characteristic marker for perisomatic-targeting cells. Scale bar, $10 \mu \mathrm{m}$. ml, Molecular layer.

11 cells) (Fig. $1 B$; supplemental Fig. $1 A$, available at www. jneurosci.org as supplemental material). They furthermore expressed the classical fast-signaling properties of this IN type $\left[R_{\mathrm{i}}\right.$ : $145.6 \pm 22.4 \mathrm{M} \Omega$; 34 cells; $\tau_{\mathrm{m}}$ : $10.1 \pm 0.9 \mathrm{~ms}, 12$ cells; action potential half-duration: $0.35 \pm 0.02 \mathrm{~ms}, 20$ cells; maximal discharge frequency: $208 \pm 16 \mathrm{~Hz}, 20$ cells (Bartos et al., 2002; Doischer et al., 2008)].

In summary, Lhx6-EGFP is abundantly expressed in juvenile fast-spiking PV-INs with perisomatically located axon and thereby fulfils the criterion of a reliable marker for the identification of this cell type.

\section{First GABAergic synapses on perisomatic-targeting cells are excitatory}

To explore a broad period in the developmental regulation of GABAergic inputs, we determined when the first functional GABAergic synapses on perisomatic-targeting cells are established (Fig. 2). Recordings from Lhx6-EGFP-positive cells were performed at various postnatal ages starting from $\mathrm{P} 0$. Pharmacologically isolated $\mathrm{GABA}_{\mathrm{A}}$ receptor-mediated postsynaptic currents (IPSCs) were evoked by extracellular stimulation in the gcl (Fig. 2A). If IPSCs could not be instantaneously triggered, we stepwise increased the stimulus intensity and systematically varied the position of the stimulus electrode in the gcl, including areas close to the hilus border and the weakly established molecular layer, to exclude failures caused by insufficient depolarization of presynaptic fibers. Interestingly, IPSCs could not be elicited in Lhx6-EGFP cells at P0-P1 (6 cells) and in only 2 of 6 cells at P2 (Fig. 2A). Reliability in IPSC induction abruptly increased to $96 \%$ at P3-P5 (24 of 25 cells) (Fig. 2A). IPSCs could be blocked by $\mathrm{SR} 95531(2-5 \mu \mathrm{M})$, indicating their $\mathrm{GABA}_{\mathrm{A}}$ receptormediated nature ( 3 cells; $94 \pm 1 \%$ block) (Fig. $2 A$ ). Notably, the onset of evoked glutamate receptor-mediated synaptic transmission in early postnatal perisomatic-targeting cells followed a similar time course (probability: 15\% at P0-P2, 3 of 20 cells; $91 \%$ at P3-P5, 20 of 22 cells) (Fig. 2A). Thus, our data indicate that first inputs on Lhx6-EGFP cells are established after birth at $\sim \mathrm{P} 3$ and contradict previous investigations, which suggested a sequential formation of first GABAergic and second glutamatergic synapses in the hippocampus (Ben-Ari, 2002; Gozlan and Ben-Ari, 2003)

To examine the reversal potential of synaptically evoked $\mathrm{GABA}_{\mathrm{A}}$ receptor-mediated IPSPs $\left(E_{\text {syn }}\right)$, we performed perforated-patch recordings from Lhx6-EGFP cells at different postnatal ages (Fig. $2 B-D)$. We used the ionophore gramicidin to keep the intracellular $\mathrm{Cl}^{-}$ concentration unperturbed. Early formed GABAergic synapses (P3P6) had an $E_{\text {syn }}$ of $-32.9 \pm 3.0 \mathrm{mV}$ (6 cells), which was significantly more positive than the corresponding average resting membrane potential $\left(V_{\text {rest }}\right)$ of $-60.8 \pm 1.1 \mathrm{mV}$ (Fig. $\left.2 C, D\right)(31$ cells; $p<0.001$ ), implying depolarizing synaptic inhibition. A linear fit to $E_{\text {syn }}$ across the developmental age studied (P3-P21) revealed a significant change toward more hyperpolarized values (Fig. 2D) (27 cells in total; correlation coefficient: $-0.72 ; p<0.001) . E_{\mathrm{syn}}$ in early postnatal Lhx6-EGFP cells was significantly more positive than in perisomatic-targeting cells at juvenile stages $\left(\mathrm{P} 18-\mathrm{P} 21 ; E_{\mathrm{syn}}=\right.$ $-55.6 \pm 3.4 \mathrm{mV} ; 5$ cells; $p=0.002)$. In contrast, $V_{\text {rest }}$ underwent minor changes from $-60.8 \pm 1.1 \mathrm{mV}$ at $\mathrm{P} 3-\mathrm{P} 6$ to $-64.9 \pm 1.1 \mathrm{mV}$ at P18-P21 (22 cells; in total P3-P21: 80 cells) (Fig. $2 F$ ) (correlation coefficient: $-0.26 ; p=0.021)$. Thus, the driving force for GABAergic signaling $\left(E_{\text {syn }}-V_{\text {rest }}\right)$ declined from $\sim 27 \mathrm{mV}$ at P3-P6 to $\sim 10 \mathrm{mV}$ at P18-P21 and was largely determined by changes in $E_{\text {syn }}$.

During the same developmental epoch the action potential threshold $\left(V_{\text {thr }}\right)$ did not change significantly (Fig. $\left.2 E, F\right)$ (41 cells; correlation coefficient: $-0.18 ; p=0.283)$. At P3-P6, the mean $V_{\text {thr }}$ was $-33.9 \pm 0.9 \mathrm{mV}$ and matched the average $E_{\mathrm{syn}}$ at that age (18 cells; $p=0.973$ ), whereas at $\mathrm{P} 18-\mathrm{P} 21 V_{\mathrm{thr}}$ was with $-35.1 \pm$ $1.6 \mathrm{mV}$ significantly more positive than the average $E_{\text {syn }}$ (Fig. $2 E-G)(10$ cells; $p<0.001)$. The parameters $V_{\text {rest }}$ and $E_{\text {syn }}$ changed linearly as a function of postnatal age (Fig. $2 D-G$ ). Superposition of the linear fits revealed an early postnatal period (before $\sim$ P6) with excitatory $\left(E_{\mathrm{syn}} \geq V_{\mathrm{thr}}\right)$ followed by a period (after $\sim$ P6) with shunting $\left(V_{\text {rest }} \leq E_{\text {syn }}<V_{\text {thr }}\right)$ driving force for GABAergic signaling (Fig. $2 G$ ). Thus, pharmacologically isolated $\mathrm{GABA}_{\mathrm{A}}$-mediated inputs on perisomatic-targeting cells are characterized by a progressive developmental transition from excitatory to shunting during the course of the first to second postnatal week (but see Gulledge and Stuart, 2003). 

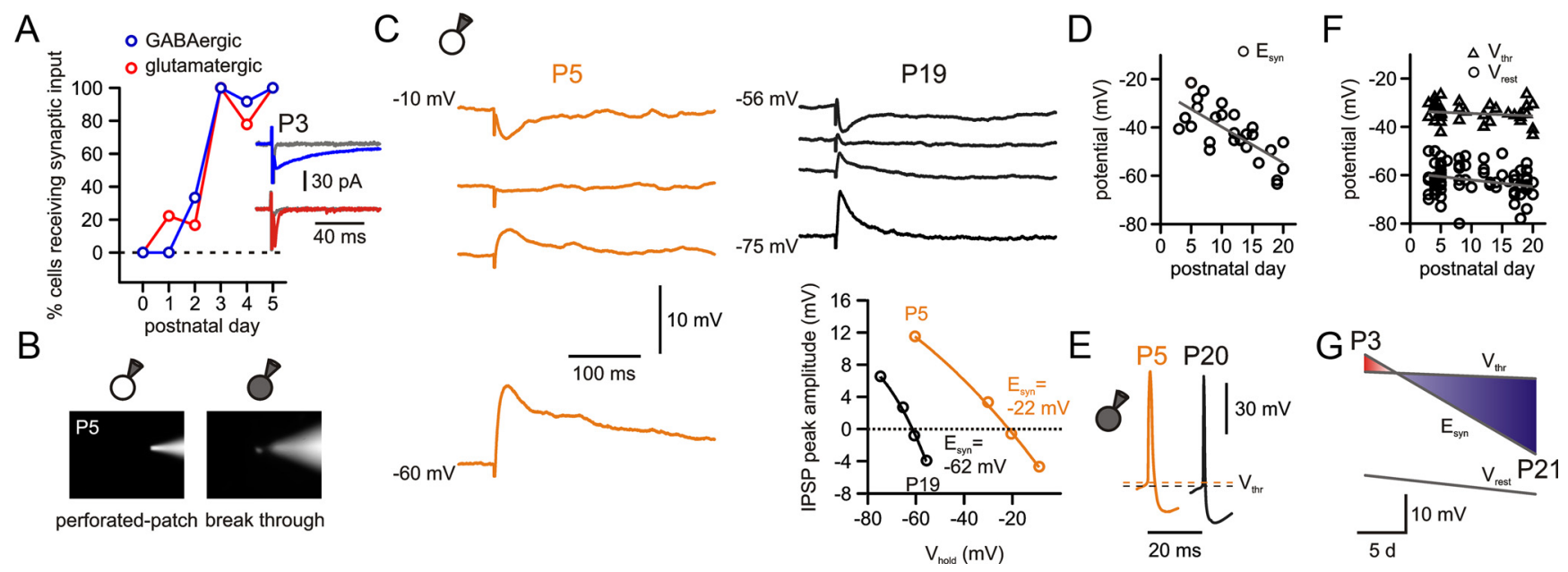

Figure 2. First formed GABAergic synapses on perisomatic-targeting cells are depolarizing. $A$, Plot summarizing the onset of functional GABAergic (blue) and glutamatergic (red) synaptic transmission on Lhx6-EGFP-expressing perisomatic-targeting cells. Inset, Average IPSC (30 single traces; in the presence of $20 \mu \mathrm{M}$ CNQX) and EPSC (in the presence of $5 \mu \mathrm{M}$ SR95531) during

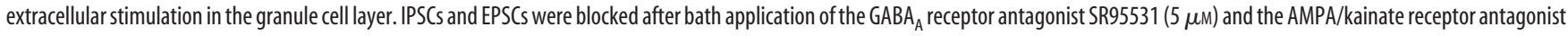
CNQX (20 $\mu \mathrm{m}$; gray), respectively. $\boldsymbol{B}$, Gramicidin perforated-patch recordings were used to measure the reversal potential of synaptically evoked IPSPs $\left(E_{\text {syn }}\right)$ in perisomatic-targeting cells. Alexa Fluor 488 was added to the pipette solution to monitor stability of the perforated-patch. Left, Epifluorescence is restricted to the recording pipette. Right, Soma of the recorded cell is labeled after spontaneous break through. $C$, Representative $\mathrm{GABA}_{\mathrm{A}}$ receptor-mediated IPSPs (average from 6-13 traces) evoked in an early postnatal (orange) and a juvenile (black) perisomatic-targeting cell at different holding potentials $\left(V_{\text {hold }}\right)$. Bottom right, IPSP peak amplitudes plotted against $V_{\text {hold }}$ to reveal $E_{\text {syn }}$ in an early postnatal and a juvenile perisomatic-targeting cell. Data were fitted with a polynomial function. $\boldsymbol{D}$, Summary plot of $E_{\text {syn }}$ over postnatal age. Gray line indicates a linear fit. $\boldsymbol{E}$, Action potential threshold $\left(V_{\text {thr }}\right.$, dashed line) was similar in early postnatal (orange) and juvenile (black) perisomatic-targeting cells. $\boldsymbol{F}$, Plot of resting membrane potential $\left(V_{\text {rest }}\right)$ and $V_{\text {thr }}$ over age. Gray lines correspond to linear functions fitted to the data. $\boldsymbol{G}$, Superposition of three lines representing linear fits to $E_{\text {syn }}, V_{\text {thr }}$ and $V_{\text {rest }}$ in perisomatic-targeting cells at P3-P21 emphasizing the developmental change of GABAergic signaling from excitatory (red area; $E_{\text {syn }} \geq V_{\text {thr }}$ ) to shunting (blue area; $V_{\text {rest }} \leq E_{\text {syn }}<V_{\text {thr }}$ ).

\section{Depolarizing GABAergic signaling facilitates action potential initiation at early postnatal stages}

Since the average $E_{\text {syn }}$ at early postnatal development was precisely at $V_{\text {thr }}$ (Fig. $2 D, F$ ), we asked whether the depolarization by GABAergic inputs is sufficient to recruit perisomatic-targeting cells. To address this question, we performed whole-cell recordings with a pipette solution that mimicked the early postnatal $E_{\text {syn }}$ measured in perforated-patch recordings by adjusting the intracellular $\mathrm{Cl}^{-}$concentration to $\sim 46 \mathrm{~mm}$ ("early postnatal $E_{\text {syn }}$ " pipette solution; see Materials and Methods). In 7 of 11 Lhx6EGFP-positive perisomatic-targeting INs (64\%), action potentials were evoked upon extracellular stimulation of pharmacologically isolated GABAergic inputs (Fig. $3 A$, B, blue traces) (see Materials and Methods). The same result was obtained in the perforatedpatch configuration in which action potentials could be generated in 4 of 6 cells (67\%; data not shown). Similarly, stimulation of glutamatergic synaptic inputs in the presence of the $\mathrm{GABA}_{\mathrm{A}}$ receptor blocker SR95531 $(2-5 \mu \mathrm{M})$ elicited action potentials in 10 of 14 cells (Fig. $3 A, B$, red traces), indicating that in contrast to the juvenile situation (Alle et al., 2001) glutamatergic inputs are not strong enough to robustly induce perisomatic-targeting cell firing. Thus, both GABAergic and glutamatergic inputs evoke action potentials in early postnatal perisomatic-targeting cells with the same moderate reliability (65\% vs $71 \%$, respectively) (Fig. $3 B$ ). In contrast, simultaneous activation of both types of fibers readily elicited action potentials in all tested neurons (Fig. $3 A, B$, black traces) (15 cells), indicating that GABAergic inputs can boost the recruitment of perisomatic-targeting cells when glutamatergic synapses are cooperatively active. Indeed, when SR95531 was applied in this configuration spike-probability markedly decreased to $8 \pm 4 \%$ of control (Fig. 3C,D) $(5$ cells; $p=$ $0.024)$. Notably, in 3 of 5 cells action potential generation was completely abolished. In contrast, in the juvenile situation shunting inhibition failed to evoke action potentials ( 5 of 5 cells) whereas glutamatergic signaling was maximally effective in spike induction (100\%; 6 of 6 cells) (supplemental Fig. 2, available at www.jneurosci.org as supplemental material).

Next we directly compared the effect of depolarizing and shunting inhibition on activation of early postnatal perisomatictargeting cells by performing the following repatching experiment: first, we recorded from P3-to-P6-old Lhx6-EGFP-INs using the "early postnatal $E_{\text {syn }}$ " pipette solution and evoked action potentials by extracellular stimulation of GABAergic and glutamatergic inputs with an intensity resulting in a discharge probability of $47 \pm 6 \%$ ( 6 cells). Second, we repatched the same neuron with a pipette solution containing $15.2 \mathrm{mM} \mathrm{Cl}^{-}$thereby reproducing the measured average "juvenile $E_{\text {syn }}$ " (see Materials and Methods). Although the extracellular stimulation intensity was kept constant, the probability of action potential generation decreased significantly to $7 \pm 5 \%$ (Fig. $3 E, F)(6$ cells; $p<0.001)$. In 4 cells, action potential initiation vanished completely. Finally, re-repatching the same cell with "early postnatal $E_{\text {syn }}$ " pipette solution restored spiking to control values $(42 \pm 10 \%, 4$ cells; $p=$ 0.762 ) (Fig. 3E, F). Together, our data indicate that the depolarizing effect of evoked IPSPs supports action potential generation in Lhx6-EGFP ${ }^{+}$neurons and thereby facilitates the efficient recruitment of early postnatal perisomatic-targeting cells in the developing DG circuitry.

\section{Discussion}

Here, we show that Lhx6-EGFP-expressing perisomatictargeting INs in the DG receive their first functional GABAergic synaptic inputs after birth $(\sim \mathrm{P} 3) . \mathrm{GABA}_{\mathrm{A}}$ receptor-mediated transmission at these first inputs is excitatory $\left(E_{\text {syn }} \geq V_{\text {thr }}\right)$ and changes to shunting $\left(V_{\text {rest }} \leq E_{\text {syn }}<V_{\text {thr }}\right.$ ) during the course of the first two postnatal weeks. A switch in the nature of $\mathrm{GABA}_{\mathrm{A}}$ signaling is caused by a gradual change in $E_{\text {syn }}$ from a value close to spike-threshold to a value close to resting voltage. In contrast, 
$V_{\text {thr }}$ shows no and $V_{\text {rest }}$ only minor alterations during the same time period. Our data appear to differ from recent investigations on the nature of $\mathrm{GABA}_{\mathrm{A}}$ mediated signaling in developing CA3 INs (Banke and McBain, 2006; Tyzio et al., 2008). In these INs the average $E_{\text {syn }}$ is $\sim 20$ $\mathrm{mV}$ more negative during the same developmental window (P4-P20) suggesting that GABAergic signaling in CA3 INs results in a shunt rather than action potential generation throughout postnatal development. One explanation for this apparent difference may be that a shift from excitation to shunting is specific for perisomatic-targeting cells but not other IN types. A further likely explanation is that previous investigations may not have enclosed the time window during which first functional GABAergic synapses are formed. In fact, GABAergic innervation of INs in the CA areas is already present before birth (Gozlan and Ben-Ari, 2003) and we show that the change from excitatory to shunting transmission emerges in a short period of time after the formation of first GABAergic synapses.

In PCs, $E_{\text {syn }}$ undergoes a marked hyperpolarizing developmental shift (BenAri, 2002). It is well established that this is caused by a change in the transmembrane $\mathrm{Cl}^{-}$gradient (Kaila, 1994; Ben-Ari, 2002), which results from the predominant expression of the $\mathrm{Cl}^{-}$uptake-mediating transporter NKCC1 at early postnatal development and the increasing expression of $\mathrm{KCC} 2$, leading to $\mathrm{Cl}^{-}$extrusion, at mature stages (Rivera et al., 1999; Yamada et al., 2004) (but see Rheims et al., 2009). In agreement with recent investigations in hippocampal INs, our data suggest that the development of synaptic inhibition on PV-INs differs from PCs (Banke and McBain, 2006) and may be explained by a predominant contribution of NKCC1 to $E_{\text {syn }}$ at early postnatal (Rivera et al., 1999; Yamada et al., 2004) and of both transporters to $E_{\text {syn }}$ at juvenile stages (Banke and McBain, 2006).

What is the functional role of excitatory versus shunting GABAergic signals in perisomatic-targeting cells? Consistent with previous studies, $\mathrm{GABA}_{\mathrm{A}}$ receptormediated synaptic activation may promote wiring, synapse formation, and functional maturation of cortical circuits (McAllister et al., 1996; Nakagami et al., 1997; Ben-Ari, 2002). Boosting spike induction via GABAergic synapses may be of key importance when network connectivity is low (Doischer et al., 2008). Indeed our data indicate that glutamatergic and GABAergic innervation of perisomatic-targeting cells is initialized at similar timescales when the strength of both types of inputs is weak (Fig. $3 A, B$ ). A conjoint activation of ${ }^{* *} p<0.01$.
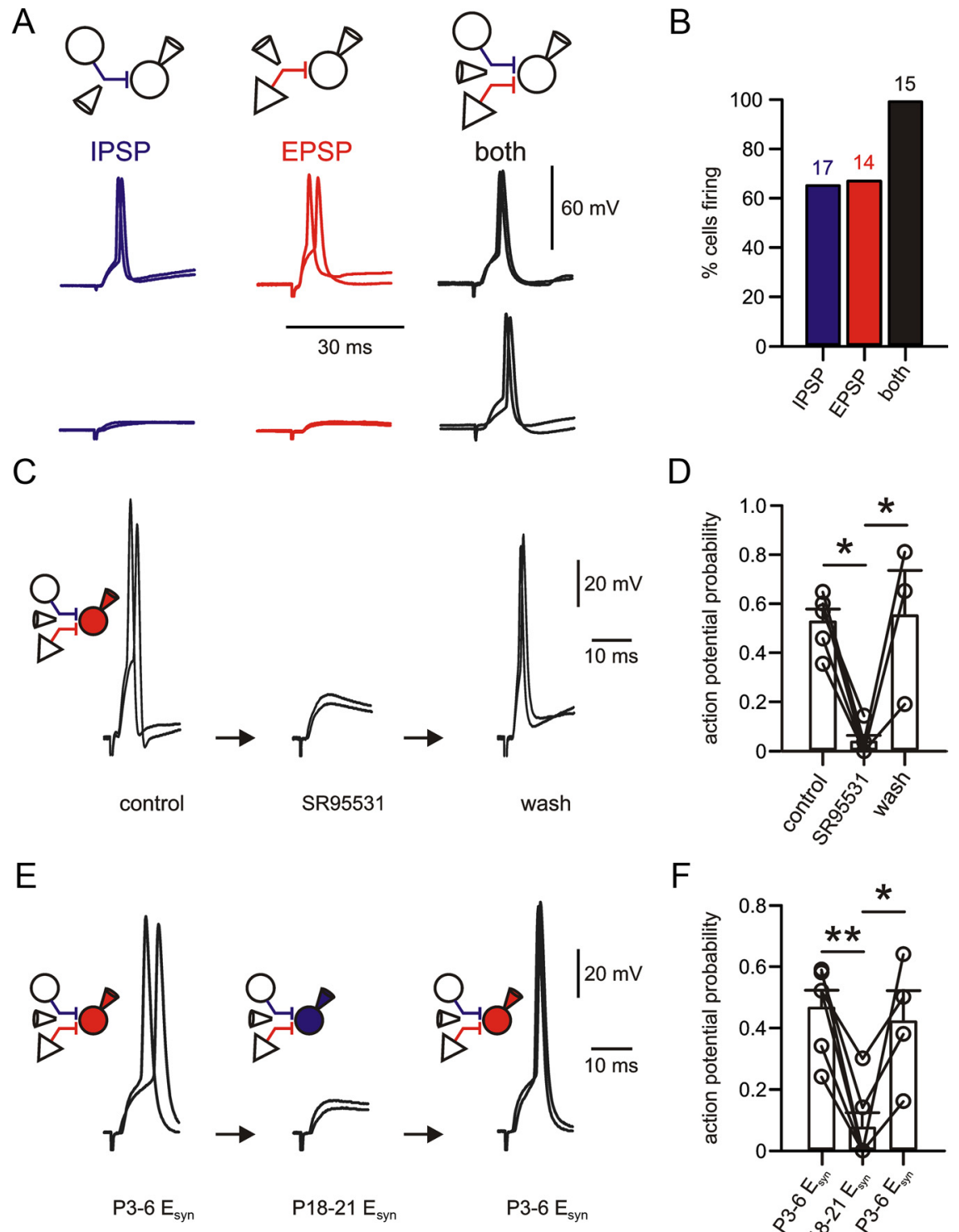

F

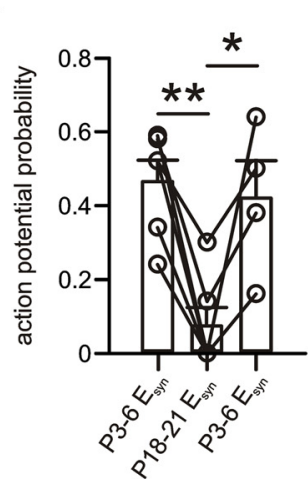

Figure 3. Depolarizing GABAergic signaling facilitates action potential generation in early postnatal perisomatic-targeting cells. $A$, Top, Schematic illustration of the experimental configuration. Bottom, Two examples are shown for extracellular activation of presynaptic GABAergic fibers (blue) in the presence of $4 \mathrm{~mm}$ kynurenic acid, of glutamatergic fibers (red) in the presence of $5 \mu \mathrm{m}$ SR95531, or both GABAergic and glutamatergic fibers (black) in P3-P6 perisomatic-targeting cells $\left(V_{\text {hold }}=V_{\text {rest }}\right)$. Two traces are superimposed. Recordings were performed with a pipette solution mimicking the native internal $\mathrm{Cl}^{-}$concentration at P3-P6 ("early postnatal $E_{\text {syn }}$ " solution) estimated from perforated-patch recordings (Fig. 2). $\boldsymbol{B}$, Bar graph summarizing the percentage of perisomatic-targeting cells discharging upon stimulation of pharmacologically isolated GABAergic, glutamatergic, or both types of presynaptic inputs (values above bars represent number of cells). C, Extracellular stimulation intensity was chosen to evoke action potentials in early postnatal perisomatic-targeting cells with $\sim 50 \%$ reliability ( $V_{\text {hold }}=V_{\text {resti }} 2$ superimposed traces). Middle, Blocking $\mathrm{GABA}_{\mathrm{A}}$-mediated signaling with $5 \mu \mathrm{M}$ SR95531 obstructs action potential generation. Right, Blocking effect on spike induction is reversed after washout of SR95531. D, Summary of the effect of SR95531 on discharge probability in early postnatal (P3-P6) perisomatic-targeting cells. Circles connected by lines represent single experiments (control $53 \pm 5 \%, 5$ cells; SR95531 $4 \pm 3 \%, 5$ cells; wash $55 \pm 19 \%, 3$ cells). $\boldsymbol{E}$, Left, Example of action potential initiation during recording with "early postnatal

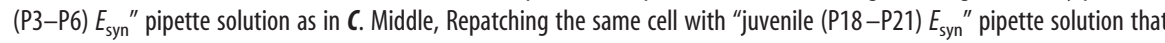
induces shunting inhibition abolishes action potential generation. Right, Re-repatching the neuron with the initial $\mathrm{P3}-\mathrm{P} 6 E_{\text {syn }}$ pipette solution restores spiking. $\boldsymbol{F}$, Bar graph summarizing discharge-probability in the experiments shown in $\boldsymbol{E}$. ${ }^{*} p<0.05$;

perisomatic-targeting cells by GABA and glutamate may be critically involved in the emergence of slow rhythmic activity patterns occurring at low frequencies $[0.1-0.33 \mathrm{~Hz}$ (Ben-Ari, 2002; Sipilä et al., 2009)], which are considered important for the maturation of early formed neuronal networks (Ben-Ari, 2002). In contrast, shunting inhibition in the mature network controls 
spike timing in both INs and PCs when the network is in an excited state, a crucial prerequisite for the emergence of coherent oscillations and the synchronization of principal cell assemblies (Wang and Buzsáki, 1996; Vida et al., 2006; Bartos et al., 2007; Doischer et al., 2008). In conclusion, GABAergic signaling in perisomatic-targeting cells switches from "classical" excitation at early postnatal to shunting at juvenile stages, which goes hand in hand with a drastic functional shift from boosting spike induction (this study) to controlling spike timing (Vida et al., 2006).

\section{References}

Alle H, Jonas P, Geiger JR (2001) PTP and LTP at a hippocampal mossy fiber-interneuron synapse. Proc Natl Acad Sci U S A 98:14708-14713.

Altman J, Das GD (1965) Autoradiographic and histological evidence of postnatal hippocampal neurogenesis in rats. J Comp Neurol 124:319-335.

Banke TG, McBain CJ (2006) GABAergic input onto CA3 hippocampal interneurons remains shunting throughout development. J Neurosci 26:11720-11725

Bartos M, Vida I, Frotscher M, Meyer A, Monyer H, Geiger JR, Jonas P (2002) Fast synaptic inhibition promotes synchronized gamma oscillations in hippocampal interneuron networks. Proc Natl Acad Sci U S A 99:13222-13227.

Bartos M, Vida I, Jonas P (2007) Synaptic mechanisms of synchronized gamma oscillations in inhibitory interneuron networks. Nat Rev Neurosci 8:45-56.

Ben-Ari Y (2002) Excitatory actions of gaba during development: the nature of the nurture. Nat Rev Neurosci 3:728-739.

Cobos I, Calcagnotto ME, Vilaythong AJ, Thwin MT, Noebels JL, Baraban SC, Rubenstein JL (2005) Mice lacking Dlx1 show subtype-specific loss of interneurons, reduced inhibition and epilepsy. Nat Neurosci 8:1059-1068.

Doischer D, Hosp JA, Yanagawa Y, Obata K, Jonas P, Vida I, Bartos M (2008) Postnatal differentiation of basket cells from slow to fast signaling devices. J Neurosci 28:12956-12968.

Du J, Zhang L, Weiser M, Rudy B, McBain CJ (1996) Developmental expression and functional characterization of the potassium-channel subunit $\mathrm{Kv} 3.1 \mathrm{~b}$ in parvalbumin-containing interneurons of the rat hippocampus. J Neurosci 16:506-518.

Freund TF, Buzsáki G (1996) Interneurons of the hippocampus. Hippocampus 6:347-470.

Fuchs EC, Zivkovic AR, Cunningham MO, Middleton S, Lebeau FE, Bannerman DM, Rozov A, Whittington MA, Traub RD, Rawlins JN, Monyer H (2007) Recruitment of parvalbumin-positive interneurons determines hippocampal function and associated behavior. Neuron 53:591-604.

Garaschuk O, Hanse E, Konnerth A (1998) Developmental profile and synaptic origin of early network oscillations in the CA1 region of rat neonatal hippocampus. J Physiol 507:219-236.

Geiger JR, Lübke J, Roth A, Frotscher M, Jonas P (1997) Submillisecond AMPA receptor-mediated signaling at a principal neuron-interneuron synapse. Neuron 18:1009-1023.

Gozlan H, Ben-Ari Y (2003) Interneurons are the source and the targets of the first synapses formed in the rat developing hippocampal circuit. Cereb Cortex 13:684-692.

Gulledge AT, Stuart GJ (2003) Action potential initiation and propagation in layer 5 pyramidal neurons of the rat prefrontal cortex: absence of dopamine modulation. J Neurosci 23:11363-11372.

Hollrigel GS, Ross ST, Soltesz I (1998) Temporal patterns and depolarizing actions of spontaneous $\mathrm{GABA}_{\mathrm{A}}$ receptor activation in granule cells of the early postnatal dentate gyrus. J Neurophysiol 80:2340-2351.

Kaila K (1994) Ionic basis of GABAA receptor channel function in the nervous system. Prog Neurobiol 42:489-537.

Kraushaar U, Jonas P (2000) Efficacy and stability of quantal GABA release at a hippocampal interneuron-principal neuron synapse. J Neurosci 20:5594-5607.

Leinekugel X, Tseeb V, Ben-Ari Y, Bregestovski P (1995) Synaptic GABA activation induces $\mathrm{Ca} 2+$ rise in pyramidal cells and interneurons from rat neonatal hippocampal slices. J Physiol 487:319-329.

Mann EO, Paulsen O (2007) Role of GABAergic inhibition in hippocampal network oscillations. Trends Neurosci 30:343-349.

McAllister AK, Katz LC, Lo DC (1996) Neurotrophin regulation of cortical dendritic growth requires activity. Neuron 17:1057-1064.

Nakagami Y, Saito H, Matsuki N (1997) The regional vulnerability to blockade of action potentials in organotypic hippocampal culture. Brain Res Dev Brain Res 103:99-102.

Owens DF, Boyce LH, Davis MB, Kriegstein AR (1996) Excitatory GABA responses in embryonic and neonatal cortical slices demonstrated by gramicidin perforated-patch recordings and calcium imaging. J Neurosci 16:6414-6423.

Rheims S, Minlebaev M, Ivanov A, Represa A, Khazipov R, Holmes GL, Ben-Ari Y, Zilberter Y (2008) Excitatory GABA in rodent developing neocortex in vitro. J Neurophysiol 100:609-619.

Rheims S, Holmgren CD, Chazal G, Mulder J, Harkany T, Zilberter T, Zilberter Y (2009) GABA action in immature neocortical neurons directly depends on the availability of ketone bodies. J Neurochem 110:1330-1338.

Rivera C, Voipio J, Payne JA, Ruusuvuori E, Lahtinen H, Lamsa K, Pirvola U, Saarma M, Kaila K (1999) The $\mathrm{K}^{+} / \mathrm{Cl}^{-}$co-transporter KCC2 renders GABA hyperpolarizing during neuronal maturation. Nature 397:251-255.

Sipilä ST, Huttu K, Yamada J, Afzalov R, Voipio J, Blaesse P, Kaila K (2009) Compensatory enhancement of intrinsic spiking upon NKCC1 disruption in neonatal hippocampus. J Neurosci 29:6982-6988.

Tyzio R, Minlebaev M, Rheims S, Ivanov A, Jorquera I, Holmes GL, Zilberter Y, Ben-Ari Y, Khazipov R (2008) Postnatal changes in somatic gammaaminobutyric acid signalling in the rat hippocampus. Eur J Neurosci 27:2515-2528.

Vida I, Bartos M, Jonas P (2006) Shunting inhibition improves robustness of gamma oscillations in hippocampal interneuron networks by homogenizing firing rates. Neuron 49:107-117.

Wang XJ, Buzsáki G (1996) Gamma oscillation by synaptic inhibition in a hippocampal interneuronal network model. J Neurosci 16:6402-6413.

Yamada J, Okabe A, Toyoda H, Kilb W, Luhmann HJ, Fukuda A (2004) $\mathrm{Cl}^{-}$ uptake promoting depolarizing GABA actions in immature rat neocortical neurones is mediated by NKCC1. J Physiol 557:829-841. 